\title{
Nigeria as a country of stories
}

\section{T. M. Gavristova ${ }^{1}$}

${ }^{1}$ P. G. Demidov Yaroslavl State University, 14 Sovetskaya str., Yaroslavl 150003, Russian Federation

DOI: $10.18255 / 1996-5648-2021-2-152-163$

Research article Full text in Russian

The article is dedicated to the phenomenon of storytelling and its evolution in the context of globalization and digitalization. The choice of Nigeria as an object of study is not accidental. The oral tradition in Nigeria has developed dynamically over the centuries. Nigerian literature is considered to be a successor of the traditions of world classics. It was the writers - the "children of Herodotus» - who assumed the function of recording and relaying stories that, being biased, led to the destruction of a number of stereotypes regarding Africa and Africans. The traditions of storytelling appeared in literature and journalism, in television and radio broadcasting, across In-ternet. Nigerians have become active participants in TED conferences. Storytelling in Nigeria has become a profession. Within its framework, famous writers, including women, found application, overthrowing gender inequality.

Keywords: Nigeria; literature; storytelling; oral tradition; story; gender; Chimamanda Ngozi Adichi

\section{INFORMATION ABOUT AUTHORS}

\author{
Gavristova, Tatiana M. | E-mail: tanja1994@mail.ru \\ Doc. Sc. (History), Professor
}




\section{Нигерия - страна историй}

\section{Т. М. Гавристова ${ }^{1}$}

${ }_{1}^{1}$ Ярославский государственный университет им. П. Г. Демидова, ул. Советская, 14, Ярославль, 150003, Российская Федерация

DOI: 10.18255/1996-5648-2021-2-152-163

УДК 94 (669)

Научная статья

Полный текст на русском языке

В статье рассматривается френомен сторителлинга и его эволюция в условиях глобализации и дигитализации. Выбор Нигерии как объекта исследования не случаен. Устная традиция в Нигерии на протяжении веков динамично развивалась. Нигерийская литература по праву считается продолжательницей традиций мировой классики. Именно писатели «дети Геродота» - возложили на себя фрунцию фриксации и ретрансляции историй, которые, будучи ангажированными, привели к разрушению ряда стереотипов в отношении Африки и африканцев. Традиции сторителлинга проявились в литературе и публицистике, в теле- и радиовещании, в сети Интернет. Нигерийцы стали активными участниками TED-конференций. Сторителлинг в Нигерии превратился в профессию. В его рамках нашли применение известные писатели, в том числе женщины, низвергнув гендерное неравенство.

Ключевые слова: Нигерия; литература; сторителлинг; устная традиция; история; гендер; Чимаманда Нгози Адичи

\section{ИНФОРМАЦИЯ ОБ АВТОРАХ}

\begin{tabular}{l|l} 
Гавристова, Татьяна Михайловна & $\begin{array}{l}\text { E-mail: tanja1994@mail.ru } \\
\text { Доктор исторических наук, профессор }\end{array}$
\end{tabular}

$$
\begin{aligned}
& \text { «В начале было Слово, } \\
& \text { и Слово было у Бога, } \\
& \text { и Слово было Бог» } \\
& \text { (Ин. 1:1.) }
\end{aligned}
$$

Устная традиция - как средство передачи знаний от поколения к поколению - изначально существовала во всех регионах и главенствовала до изобретения и принятия письменности. В условиях глобализации, медиатизации и дигитализации она трансформировалась в синтетическую по форме и содержанию разновидность историко-литературного и сценического жанра и продолжает существовать на радио, телевидении, в сети 
Гавристова Т. М.

Интернет в двух плоскостях: вербальной и визуальной. В настоящее время ее можно рассматривать как проявление скевоморфизма ${ }^{1}$ в силу изменения самого формата вещания и его механизмов при одновременном сохранении и даже расширении смысловой составляющей процесса ретрансляции.

В рамках устного творчества мифы и легенды, несущие в себе волшебные образы и заряд фантазий, на протяжении веков соседствовали с реальными и героическими конструкциями (эпосами и хрониками) и были насыщены бытовыми подробностями. Балансируя между правдой и вымыслом, в расчете на достоверность они претерпели эволюцию как инструмент сохранения исторической памяти. Письменная фриксация развивалась параллельно с актуализацией их коммуникативной направленности, что привело к частичной сакрализации, догматизации и даже идеологизации ряда ставших универсальными образов и символов, например таких, как санкофра ${ }^{2}$ [1, с. 83], а также к превращению текстов в эталонные установки морали и нравственности с их последующей интеграцией в систему гуманитарных знаний.

Модули исторической и культурной памяти, подобно модулю ядра, содержат разнообразные - многовалентные - коды, которые со временем расширяют свою фрункциональность. Формируясь в недрах памяти, представления о пространстве и времени, добре и зле, своих и чужих (других) претерпевают сложную эволюцию в процессе ретрансляции, а в ходе фиксации обретают характер документа, сохраняя характерную для африканской традиции обыденность и сакральность, приумножая и преобразуя образный ряд, который становится универсальным. В историях, рассказанных и записанных африканцами, всегда есть место для героя и антигероя, пройдохи-трикстера и самого рассказчика, который может выступать от лица каждого из названных персонажей, повествуя об их подвигах и деяниях и тиражируя разного рода клише. В Нигерии, например, это упоминания о языке «говорящих" барабанов, традиционной еде, лесах и дорогах, о духах и богах йоруба: Шанго ${ }^{3}$, Огуне ${ }^{4}$, абику ${ }^{5}$, о предприимчивости народа игбо, представителей которого нередко именуют «африканскими евреями» или «японцами», а на рубеже XX века - о различного рода мошенничествах

${ }^{1}$ Скевоморфизм \{от англ: skeuomorph (скюаморф); от греч.: бкєи̃оৎ (сосуд, орудие)

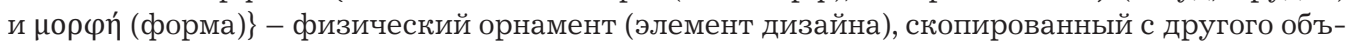
екта, изготовленный из других материалов и иными методами.

${ }^{2}$ Санкофа - в буквальном переводе с акан: «Вернись и возьми!»; один из символов адинкра; птица, оглядывающаяся назад, в прошлое; в настоящее время образ санкофы нередко ретранслируется в контексте необходимости сохранения исторической памяти.

${ }^{3}$ Шанго - громовержец, бог Огня в мифологии йоруба.

${ }^{4}$ Огун - бог войны и железа, покровитель кузнецов, охотников, путешественников; бог дорог; покровитель интеллектуалов; один из любимых персонажей Воле Шойинки, с которым он нередко себя сопоставляет.

${ }^{5}$ Абику - в буквальном переводе с языка йоруба: рожденный, чтобы умереть; в мифологии йоруба дух, живущий на грани миров живых, мертвых и еще не рожденных. 
(например, о нигерийских письмах, ставших прообразом спама, известных под названием $\left.419^{6}\right)$ и т. д.

На исходе XX века Афррика пережила «бум» в развитии книжной культуры. В настоящее время в странах континента идет активный процесс накопления и осмысления эмпирического (историко-культурного) материала. Писатели, будучи его хранителями и ретрансляторами, в поисках исторической «правды» первыми обратились к национальной и международной аудитории, интеллектуалам и массовому читателю. Создание нарративов с момента возникновения современной африканской литературы шло на стыке истории и психологии, философии и литературы, с одной стороны, в силу дефицита профрессиональных историков и ученых. С другой - в эпоху постмодерна именно литераторы и историки начали эксперименты в границах мега- и метажанров и в условиях их ангажированности обеспечили себе прорыв на мировой книжный рынок.

На фоне глобальной цифровизации истории в жанре non-fiction оказались особенно популярны в среде молодых и искушенных читателей. В настоящее время они широко тиражируются в виде открытых коммуникативных посланий как часть повседневного дискурса. Их смысловая наполненность определена богатством литературно-художественных традиций континента - тем, что В. Марков (В. И. Матвей) назвал «монументальной памятью» предков [2, с. 90], а M. М. Бахтин - «памятью жанра». Веками присущая устным рассказам склонность к парадоксам и обновлению повлекла за собой то, что реальность трансорормировалась в миф с его символами и образами, возникшими благодаря осмыслению повседневности. На их основе сложились вполне достоверные истории, ретрансляция которых напрямую связана с расширением их «вместимости» - «вместимости» жанра, который «живет настоящим, но помнит свое прошлое, свое начало» [3, с. 178-179]. О «вечной» преемственности жанров писал в своих трудах и Н. Фрай [4].

Историческая память сохранила пословицы и поговорки, сказки и песни, каламбуры и наставления, хроники и жития. Они играли и продолжают играть роль кодов, раскрывающих связь времен, а также паттернов и мемов, передаваемых от человека человеку посредством речи, письма, видео и подверженных естественному отбору, мутации и селекции [5].

В Нигерии, крупнейшей по численности населения стране Африки, становление постколониального дискурса связано с деятельностью Воле Шойинки, - выдающегося писателя, драматурга и публициста (он родился в 1934 г.), по этнической принадлежности йоруба, первым из африканцев удостоенного Нобелевской премии в области литературы в 1986 году, - и тех, кого он остроумно назвал “детьми Геродота» ${ }^{7}$.

${ }^{6}$ Адаоби Триша Обайне Нваубани (родилась в 1976 г.) - писатель, эссеист; ее дебютный роман «Я вряд ли вернусь» (2009 г.) в 2010 г. был удостоен премии писателей Содружества за лучший дебют (Африка); постоянно живет в Нигерии.

7 «Дети Геродота» - так называлась лекция писателя, поэта, драматурга, публициста Воле Шойинки. Она была прочитана на открытии международной конференции («Шойинковские чтения») в феврале 2012 года в Университете Южной Африки (UNISA). Многогран- 
Гавристова Т. М.

Чинуа Ачебе (1930-2013), Киприан Эквенси (1921-2007), Джон Маноние (1929-1999), Элечи Амади (1934-2016), Флора Нвапа (1931-1993), Нкем Нванкво (1936-2001), Бен Окри (родился в 1959 г.), Бучи Эмечета (1944-2017), Чимаманда Нгози Адичи (родилась в 1977 г.), Теджу Коул (родился в 1975 г.) и другие писатели, преимущественно игбо и йоруба, возложили на себя миссию, заданную «отцом истории» ${ }^{8}$ Вдохновленные призывом В. Шойинки («Пора африканцам от своего имени говорить об Африке!» [6, p. 183]), они встали на путь презентации и репрезентации истории и культуры континента, воздавая дань поколениям их малоизвестных хранителей и просто хорошим рассказчикам, сознавая особую - неразрывную - связь прошлого, настоящего и будущего, характерную для африканской традиции.

Для В. Шойинки Слово (с большой буквы - прим. автора) всегда много значило. Оно несло в себе множество кодов, разгадка которых стала делом читателей, слушателей, персонажа пьесы «Дорога» (1965 г.). Слово хранило сакральность как связующее звено устной истории и нарратива, культурной идентичности и исторической памяти. Логос даровал африканцам право Голоса (с большой буквы - прим. автора); как следствие, они получили возможность быть «услышанными». Сделать Африку "видимой» (вопреки стереотипу о том, что она не имеет своей истории и культуры), открыть ее заново для национальной и международной аудитории - такова была миссия «говорящих» и «пишущих».

В XXI веке ироничные формулы, типа «Африка - не страна» (\#africaisnotacountry), и аналогичная, прямо противоположная по смыслу, «Афррика - это страна» (\#africaisacountry), с легкой руки афрополитов ${ }^{9}$, «африканцев мира», преимущественно нигерийского происхождения, живущих в Европе и Америке [7], стали мировыми хэштегами. Обозначив границы реализуемой задачи, они были нацелены на то, чтобы не просто раскрыть потенциал Нигерии как крупнейшего по численности населения дина-

ность ее смысла открывала перед присутствующими на форуме исследователями (среди них была автор данной статьи) необъятное поле деятельности, направленной на изучение истории Африки, которая сравнительно недавно рассматривалась как континент «без истории». По мнению В. Шойинки, развенчать стереотипы должны продолжатели традиций, заложенных «отцом истории».

${ }^{8} \mathrm{~B}$ обществе, где исторические знания базировались на устной традиции и выживали благодаря коллективной памяти, где, по приблизительным оценкам современных исследователей, всего 10 \% населения обладали азами грамотности, то есть умели читать и писать, Геродот (480-420 гг. до н.э.), зафиксировав существующую информацию письменно, сохранил ее для многих поколений читателей, создав новый жанр повествовательной историографии, синтезировав эпос и хронику, логику и эмоцию, не избежав, как принято считать, ни эгоцентризма, ни мифотворчества.

${ }^{9}$ Афрополитизм - интеллектуальная парадигма, возникшая за пределами Африки в среде поколения, рожденного на рубеже 1970-1980 годов. Принадлежащие к нему писатели, публицисты, блогеры предприняли контратаку на общественное мнение с целью признания достижений африканцев и развенчания стереотипов. Профессионалы, ориентированные на успех и карьерный рост, видели в афрополитизме новую идентичность и мораль, альтернативу космополитизму и позиционировали себя не как граждане, а как африканцы мира. 
мично развивающегося государства и литературной державы, не просто заявить о себе и таким образом создать и упрочить позитивный образ нации и континента. Следовало продемонстрировать многообразие и подлинность культур, в недрах которых черпали вдохновение писатели и поэты, художники и скульпторы, африканцы и не африканцы. Эфрфект присутствия нигерийцев в литературной, художественной и академической среде превзошел все ожидания.

В условиях динамичной экстроверсии знаний английский язык (государственный язык Нигерии) сыграл роль своего рода «пропуска» в мировую интеллектуальную среду. Приняв нигерийцев, она сделала их своими, расширив границы их ангажированности и интереса к историко-культурному наследию Нигерии и Африки в целом со стороны представителей других рас, этносов, культур. Так возникла в 1962 г. «оранжевая серия» (Heinemann's African Writers Series); она в немалой степени способствовала популяризации творчества писателей континента в Великобритании и, как следствие, в США, Индии, Австралии, радикально изменив круг чтения африканцев и не африканцев. Осознание того, что африканские реалии вполне могут быть объектом писательского, исследовательского и читательского интереса, «открыло» Африку самим африканцам, о чем многократно упоминали в своих произведениях, интервью и публичных лекциях Т. Коул и Ч. Н. Адичи признанные фрлагманы нигерийской литературы. Газеты «Guardian» и «The New York Times» относят их к числу самых влиятельных африкканцев мира, олицетворяющих собой славу Нигерии.

Национальная литература Нигерии, в значительной мере благодаря влиянию культуртрегеров, по праву считается продолжательницей традиций мировой классики. В отличие от европейских аналогов (английской, французской, немецкой, русской литературы), рожденных вербальной культурой, она в гораздо большей мере связана с устной традицией, которая - как и литература в свою очередь - возникла в недрах контекстуальности. Главенствующую роль играло не столько слово (то есть сказанное), сколько обстоятельства, при которых оно было произнесено. Кто сказал, когда, где и кому, всегда было гораздо важнее смысла сказанного. В обществе, где устное творчество на протяжении длительного времени оставалось едва ли не единственной альтернативой колониальному нарративу, авторитет рассказчика был высок, как и престиж литературного труда.

Сторителлинг, наряду с собственно писательством, остается любимым занятием как молодых и начинающих, так и всемирно известных литераторов. В современной Нигерии огромным интересом пользуются их выступления, интервью и лекции. Аудитория разнообразна: профессионалы и те, кто только учится владеть пером, читатели, слушатели, все, кто видит в подобном общении школу жизни и фрорму коммуникации.

Писатели старшего поколения - Ч. Ачебе и В. Шойинка - работали на радио и ТВ. В 1960-1970-х годах, в условиях низкой грамотности населения, только так можно было завоевать сердца потенциальных читате- 
Гавристова Т. М.

лей и развить их вкус. Б. Эмечета, чьи романы в России так и не увидели свет, в молодости занималась психотренингом, избавляя от комплексов чернокожих лондонских иммигрантов. В общении с ними она не только использовала таланты «рассказчицы», но и культивировала материнские менторские - нотки, способствуя осознанию необходимости получения диплома теми, кто был намерен интегрироваться в новую среду.

С тех пор ситуация изменилась. Возрос уровень образованности населения. Книжные новинки стали доступнее. Увеличилось число любителей аудиокниг, тематических подкастов, TED-лекций и TED-радио. Они востребованы в ходе поездок, прогулок, за рулем. В сети большое число просмотров набирают видеоролики Т. Коула и Ч. Н. Адичи, интервью и лекции писателя В. Шойинки, историка Тойина Фалолы (родился в 1953 году) и других.

TED Talks - ежегодная конференция, инициируемая частной некоммерческой организацией TED (Technology, Entertainment, Design), созданной в 1984 г. в США с целью распространения уникальных идей в области науки и культуры. Популярность TED-выступлений особенно высока в молодежной среде, благодаря их фрормату. Выступления транслируются в сети. Нигерия успешно интегрировалась в киберпространство. Доля пользователей Интернета составляет, по разным оценкам, 62-66 \% от общего числа населения. Английский язык является основным языком вещания.

B XXI веке участниками TED-конференций стали: Крис Абани (2007 г.; тема: «Об историях из Африки»); Чимаманда Нгози Адичи (2009 г., тема: «Об опасности одной единственной истории»; 2014 г., тема: «Нам всем следует быть фреминистами»); Титилопа Сонуга (2014 г.; «Говоря в пустоту»); Лувви Аджайи (2017 г.; тема: «Чувствовать себя комфортно, когда некомфрортно»); Ннеди Окофор (2017 г.; тема: «Научно-франтастические истории о будущем Африки»); Лола Шонейн (2012 г.; тема: «Мальчики, секс и истории»); Тайе Селаси (2014 г.; тема: «Не спрашивайте, откуда, спрашивайте, где я чувствую себя своей»); Бен Окри (2016 г.; тема «Наши тайные истории»); Иджеома Умебиньо (2017 г.; тема: «Разрушение культуры молчания»); Нгози Оконджо-Ивеала (2016 г.; тема: «Как Африка может наращивать подъем») и другие писатели и публицисты. Численное превосходство женщин в массе нигерийских участников TED-конференций можно объяснить востребованностью литературных профессий и особой - гендерной - ролью рассказчицы в традиционном и современном обществах.

B TED-лекциях разговор ведется от первого лица. Истории, рассказанные нигерийцами, - не «набор достоверных фрактов» [8, р. 3], а размышления о наболевших проблемах человека и человечества. Для экономиста, экс-министра фринансов (2003-2006; 2011-2015 гг.) правительства Нигерии Н. Оконджо-Ивеала (родилась в 1954 г.) - это поиск резервов для экономического роста; для доктора медицины Сейи Ойесола - проблемы мобильных госпиталей и развитие здравоохранения. Для писателя и музыканта К. Абани - это сами истории, которые, по его мнению, являются частью нигерийской идентичности, определяя смысл, ритм и образ жизни людей. 
Н. Окофор поделилась со слушателями тем, что черпает идеи для своих блестящих научно-франтастических произведений в космологических и духовных традициях народа игбо. В них она видит истоки своего творчества. «Счастливая нигерийская феминистка» Ч. Н. Адичи (именно так, иронично, она себя позиционирует) и две другие, не столь оптимистично настроенные и явно озабоченные проявлениями мужской агрессии и виктимностью женщин, писательницы - Л. Шонеин и И. Умебиньо - акцентировали внимание на проблемах эмансипации и гендерного равенства, на том, как воспитывать детей, мальчиков и девочек.

T. Селаси, писательница нигерийско-ганского происхождения, автор термина «афрополитизм», в своей TED-лекции предложила обновленный взгляд на идею Дома (с большой буквы), отвергнув миф о национальной самобытности как основе идентичности. Для нее главное - интеллект и профессия. Где бы ни жил человек, по ее мнению, среди своих он всегда ощущает себя, как дома.

Б. Окри в своей лекции говорил о взаимодействии двух историй - публичной и частной, подчеркивая, что история (story, history), формирующая личность и идентичность, сильно отличается от того, что люди рассказывают сами о себе. Для Б. Окри важна именно подлинность истории, особенно в контексте понимания, кто есть кто на самом деле.

T. Сонуга - виртуозная рассказчица, завораживающая не только словом, но и ритмом повествования, лицедейством, игрой, подобно актерам или медиумам. Истории, «снятые с ее языка», проникали в душу. Она разыгрывала их драматургически. Ей вторила Л. Аджайи, призывая высказаться даже тех, у кого нет ни таланта, ни голоса. Для нее главное «быть собой» и «чувствовать себя комфортно, даже когда некомфортно». Такова идея ее TED-выступления [9].

Молодая писательница Олу Тимехин Адегбейе (родилась в 1991 году), несмотря на возраст, хорошо известна международной аудитории. Ее произведения переведены на норвежский и японский языки, а призыв к людям, обладающим даром устного рассказа, больше говорить «о сложном и всеобъемлющем человеческом опыте» [10], услышан. Резонанс оказался столь велик, что ведущий куратор TED Крис Андерсон признал ее TED-доклад на тему: «Кто принадлежит городу?» (2017 г.) - одной из десяти лучших историй года. В 2019 году писательница получила премию Джеральда Краака за короткое эссе в жанре нон-фикшн «Матери и мужчины», где, наряду с собственным опытом, проанализировала опыт женщин, подвергшихся насилию и, вопреки всему, нашедших в себе силы сохранить ребенка [10].

В XXI веке в Нигерии популярность обрело также расширенное телеи радиовещание в Интернете: подкастинг является одним из важнейших средств коммуникации нигерийцев, живущих на континенте, с диаспорой. Наиболее востребованы следующие из них: «Мой африканский подкаст: "Узнайте истории самых известных людей Африки”» («My African Podcast: “Get to know the stories behind the most famous names in Africa"») [12]; «He Ваше 
Гавристова Т. М.

африканское клише» («Not Your African Cliché») в Твиттере, где четыре нигерийские дамы высказывают свое мнение по разнообразным темам истории и культуры континента; «Мы только что вернулись» («WJGB - We Just Got Back»), где три нигерийские девушки делятся рассказами о радостях и печалях своего возвращения в Нигерию, и еще много разных контентов о музыке, футболе, путешествиях - любимых темах нигерийцев, живущих в Африке и за ее пределами. Наряду с современной нигерийской литературой они рождают образы и коды, с помощью которых устные истории игбо и йоруба перестают быть "мертвым кладбищем», «забытым хранилищем» тайной красоты [2, с. 3], а ретранслируются на весь мир и становятся узнаваемыми, превращаясь в «конвертируемую» валюту.

Преобладание женщин в нигерийской литературе стало особенно очевидно на заре XXI века. Королева женского романа Б. Эмечета в интервью подчеркивала: «Я выросла в Нигерии <...> В моих романах я всегда возвращаюсь в Африку. Я пишу об Африке для всех. Я пишу, как говорю. Я рассказываю < ..> Когда я сажусь писать, я < ..> вспоминаю Африку <... Нигерия - страна историй, ее женщины родились рассказчицами» $[11$, p. 448,451$]$. Мать и свекровь Бучи знали множество историй и охотно их рассказывали. Трагические и комические, они передавались из уст в уста, от поколения к поколению. Бучи слушала их девочкой и замужней дамой, даже если никто, кроме нее, не проявлял к ним интерес.

Особенно близка ей была тетка - самая старшая женщина в семье; по традиции ее называли «Большая Мать». Старая, почти слепая, вечерами она рассказывала «захватывающие» истории. Героические предания гармонично переплетались с бытовыми зарисовками, завораживая благодаря лицедейству и поэтическому воображению. «Мы сидели часами у ее ног, загипнотизированные чарующим голосом», - вспоминала Б. Эмечета в статье «Критика и идеология». «Она знакомила нас с подвигами предков, с нравами и обычаями нашего народа. Она рассказывала, словно песню пела (на одном дыхании); и лет до четырнадцати я думала, что духи вдохновляют ее» [12].

В 2005 г. Б. Эмечета стала первой и единственной (пока) африканкой, удостоенной ордена Британской империи (OBE) за большой вклад в развитие литературы. Известность ей принесли романы: «В канаве» [13] (1972 г.); «Гражданин второго сорта» [14] (1975 г.); «Выкуп за невесту» [15] (1976 г.); «Рабыня» [16] (1977 г.); «Радости материнства» [17] (1979 г.). За ними последовали автобиография «На плаву» [18] (1986 г.), повести "Двойное ярмо» [19] (1982 г.) «Гвендолен» [20] (1989 г.), «Кехинде» [21] (1994 г.), «Новое племя» [22] (1999 г.) - о проблемах колониализма, расизма, эмиграции; истории повседневной жизни африканцев в Нигерии и Великобритании. Ее герои бедные и богатые; африканцы и не африканцы; матери-одиночки и студенты; молоденькие девушки, испытывающие отчуждение в обществе белых; сироты и их приемные родители; «граждане второго сорта» (иммигранты: «особая разновидность черных», «новые кокни») - демонстрируют чудеса 
выживания в борьбе с собой и обществом, где вечное уступает сиюминутному, а духовное - материальному.

На исходе XX века в Нигерии многие считали Б. Эмечету «феминисткой» только потому, что в ее историях преобладала женская тематика. Традиция требовала от женщин воспевания деяний героев-мужчин. Сама писательница отмечала: «Я пишу о маленьких событиях повседневной жизни. Я слежу за происходящим и вижу все глазами африканской женщины. Я наблюдаю за жизнью женщин, которых знаю. Правда, я не знала, что за это меня назовут “африканской феминисткой”. Если я фреминистка, то с маленькой буквы “фр” [11, р. 369].

Гораздо больший интерес к феминизму проявила Ч. Н. Адичи. Ee TED-лекция $[23,24]$ и эссе «Дорогой Иджевеле, или феминистский манифест в пятнадцати пунктах» [25, 26], вобрали в себя то, что можно рассматривать как эпистемологию народа игбо, а во взаимосвязи с «искусством памяти» [27] - как форму образного «поминовения» прошлого и увековечения знаний о нем [28, р. 66]. Писательница полемизирует с Ч. Ачебе [29, р. 22] и Б. Эмечетой. В противовес их категоричности и назидательности она утверждает, что история не может быть однозначной [30], мотивируя тем, что разные версии одной и той же истории можно услышать из уст близких людей и свидетелей одних и тех же событий.

Детство писательницы прошло в окружении интеллектуалов университета Нигерии в Нсукке, где трудились ее родители, под сводами дома, когда-то принадлежавшего Ч. Ачебе. Подростком, она выслушала немало противоречивых, героических и романтических историй о мятежной Биафре, гражданской войне в Нигерии (1967-1970 гг.), геноциде игбо. Она ухватила их «дух», что отчетливо проявилось в романе «Половина желтого солнца» (2006 г.) [31]. Завершает повествование пространный список тех, чьи рассказы помогли ей при создании произведения.

Возможность существования и тиражирования разных версий одной и той же истории культивируется в настоящее время в литературной и академической среде. Поговорка игбо гласит: «Пусть коршун взлетит, пусть орел взлетит тоже. И, если один говорит, что другой не должен взлетать, пусть его крыло сломается» (Let the kite perch, let the eagle perch too. If one says the other should not perch, let his wing break) [29, p. 17]. Такой подход стимулировал актуализацию постколониального дискурса, в границах которого на протяжении последних десятилетий реализовала себя не только Ч. Н. Адичи. Провозглашая плюрализм мнений, она одновременно низвергла гендерное неравенство, ратуя за равноправие мужчин и женщин.

Ее роман "Американка» напрямую связан с проблемой цифровизации Африки. Его главная героиня - Ифемелу - блогер. Она преуспевала в США, где училась и работала по окончании университета, но все же вернулась на родину, где ее истории гораздо более необходимы и востребованы, чем где-либо в другой точке земного шара [32]. 
Для Т. Коула Твиттер - все равно что Йоханнесбург, Лагос, Найроби или Бруклин: это любимый город; вполне «африканское пространство». В нем каждый может найти не только собеседника или слушателя, но и единомышленника; и не обязательно «каламбурить насчет того, что африканцы давно уже сбросили набедренные повязки» [33, р. 42-43].

Сторителлинг как явление в Нигерии переживает второе рождение [34]. И если первоначально он представлял собой исключительно рассказывание историй - в семье или кругу друзей, то в настоящее время очевидным стало его превращение в искусство, профессию, ремесло, востребованное в маркетинге, рекламе, журналистике и отраженное в публицистике, научно-популярной и художественной литературе, радио- теле- и Интернет вещании. В рамках сторителлинга реализовали себя писатели и просто хорошие рассказчики и ораторы. Их таланты служат на благо нации, способствуя продвижению идей (демократических и либеральных, феминистских и экологических). Примером тому может служить и недавняя книга англо-нигерийской писательницы Бернадин Эваристо «Девушка, женщина, иная» [35], за которую она была удостоена Букеровской премии 2019 г.

\section{Ссылки}

1. Хохолькова Н. Е. Афроцентризм в США: теория и практика социокультурных трансформаций. М.: Институт Африки РАН, 2019. 194 с.

2. Марков В. (Матвей В. И.). Искусство негров. М., 2019 / СПб., 1919. 153 с.

3. Бахтин M. M. Проблемы поэтики Достоевского. М.: Художественная литература, 1972. С. 464.

4. Frye N. The Archetypes of Literature // Kenyon Review. 1951. Vol. XIII, № 1. P. 92-110.

5. Докинз Р. Эгоистичный ген. М.: Мир, 1993. 318 с.

6. Conversations with Wole Soyinka / Ed. by Biodun Jeyifo. University Press of Mississippi, Jackson, 2001. 223 p.

7. Гавристова T. M. Афрополитизм: альтернатива космополитизму или трансрормация идентичности? //Вестник Санкт-Петербургскогоуниверситета. Востоковедение и африканистика. 2017. Т. 9, № 2. С. 159-172.

8. Carr E. H. What is History? Basingstoke: Palgrave, 2001. XXIV. 188 p.

9. Toby and Iniye. 10-ted-talks-by-nigerian-authors. URL: https://www. thebookbanque.com/literary/10-ted-talks-by-nigerian-authors (да-та обращения: 10.02.2020).

10. Adegbeye O. We must tell more complex and inclusive stories about human experience. URL: https://medium.com/de-correspondent/olutimehin-adegbeyewe-must-tell-more-complex-and-inclusive-stories-about-human-experience$3679566 \mathrm{~b} 5494$ (дата обращения: 10.02.2021).

11. Emerging Perspectives on B. Emecheta / Ed. by M. Umeh. L.: Africa World press: Inc., 1996. 532 p. 
12. Emecheta B. Criticism and Ideology. URL: http://www.answers.com/topic/ buchi-emecheta\#ixzz37346FKyX (дата обра-щения: 10.02.2021).

13. Emecheta B. In the Ditch. L.: Barrie \& Jenkins, 1972. 158 p.

14. Emecheta B. Second-Class Citizen L.: Allison \& Busby, 1974. 192 p.

15. Emecheta B. The Bride Price. L.: Allison \& Busby, 1976. 168 p.

16. Emecheta B. The Slave Girl. L.: Allison \& Busby, 1977. 179 p.

17. Emecheta B. The Joys of Motherhood. L.: Allison \& Busby, 1979. 157 p.

18. Emecheta B. Head About Water. An Autobiography. L.: Heinemann, 1988. 229 p.

19. Emecheta B. Double Yoke. N.-Y.: George Braziller, 1983. 163 p.

20. Emecheta B. Gwendolen. Cambridge: Heinemann, AWS, 1994. 202 p.

21. Emecheta B. Kehinde. L.: Heinemann, African Writers Series, 1994. 144 p.

22. Emecheta B. The New Tribe. L.: Heinemann, African Writers Series, 1999. $160 \mathrm{p}$.

23. Adichie Ch. N. We Should All Be Feminists. L.: Fourth Estate, 2014. 64 p.

24. Адичи Ч. Н. «Мы все должны быть феминистками». URL: http://samcult.ru/ review/5871 (дата обращения: 10.02.2021).

25. Adichie Ch. N. Dear Ijeawele, or A Feminist Manifesto in Fifteen Suggestions. N.-Y.: Alfred A. Knopf, 2017. 80 p.

26. Адичи Ч. Н. Манифест от женщины к женщине. М.: Эксмо, 2019. 128 с.

27. Йейтс Ф. А. Искусство памяти / пер. с англ. Е. В. Малышкин. М.: Университетская книга, 1997. 400 с.

28. Chukwuma H. Igbo Oral Literature: Theory and Tradition. Abak: Belpot, 1994. $\mathrm{X}, 344 \mathrm{p}$.

29. Egbunike L. U. Narrating the Past. Orality, History \& the Production of Knowledge in the Works of Chimamanda Ngozi Adichie// A Companion to Chimamanda Ngozi Adichie / Ed. By Ernest N. Emenyonu. N.-Y.: James Currey, 2017. P. 15-29.

30. Адичи Ч. Н. Опасность одной единственной истории // История Афр-рики: люди и судьбы: сборник документов и материалов / отв. ред. Т. М. Гавристова. Ярославль, 2016. С. 12-21.

31. Адичи Ч. Н. Половина желтого солнца. М.: Фантом-Пресс, 2011. 480 с.

32. Adichi Ch. N. Americanah. N.-Y.: Knopf, 2013. 477 p.

33. Cole T. Do African Digital Natives wear glass skirts? // Journal of the Africa Literature Association. 2017. Vol. 11. P. 38-44.

34. Захарова Н. А. Женский диджитал-сторителлинг в Нигерии как форма социально-политического активизма // Азия и Африка сегодня. 2020. № 8. C. $75-80$.

35. Эваристо Б. Девушка, женщина, иная / пер. с англ. С. Э. Таска. М: Эксмо, 2021.480 c. 